\title{
Increasing the length of an estradiol with progesterone timed artificial insemination protocol with 2 controlled internal drug release devices improves pregnancy per artificial insemination in lactating dairy cows
}

\author{
M. H. C. Pereira, ${ }^{1}$ F. R. Lopes Jr., ${ }^{1}$ A. K. Munhoz, ${ }^{1}$ K. G. Pohler, ${ }^{2}$ R. V. O. Filho, ${ }^{2}$ B. I. Cappellozza, ${ }^{3}$ \\ and J. L. M. Vasconcelos ${ }^{4 *}$ \\ ${ }^{1}$ Faculdade de Medicina Veterinária e Zootecnia, Universidade Estadual Paulista (UNESP), Botucatu, SP 18618-000, Brazil \\ ${ }^{2}$ Department of Animal Science, Texas A\&M University, College Station, TX 77843 \\ ${ }^{3}$ Nutricorp, Araras, 13601-000, Brazil \\ ${ }^{4}$ Department of Animal Production, São Paulo State University, Botucatu 18168-000, Brazil
}

\section{ABSTRACT}

The objective of this study was to compare the effects of different lengths of ovulation synchronization protocols using 2 controlled internal drug release (CIDR) devices on ovarian dynamics and pregnancy outcomes in lactating dairy cows. Lactating Holstein cows $(\mathrm{n}=$ $1,979)$ were randomly assigned to receive timed artificial insemination (TAI; d 0) following 1 of 2 treatments: (1) 9 -d protocol $(\mathrm{n}=988 ; 9 \mathrm{D})$ with 2 intravaginal devices containing $1.9 \mathrm{~g}$ of progesterone (CIDR) and $2.0 \mathrm{mg}$ of estradiol benzoate on day $-11 ; 25 \mathrm{mg}$ (i.m.) of dinoprost tromethamine $(\mathrm{PG})$ and withdrawal of 1 CIDR on $\mathrm{d}-4 ; 1.0 \mathrm{mg}$ (i.m.) of estradiol cypionate, second CIDR withdrawal, and PG on $\mathrm{d}-2$; and TAI on $\mathrm{d} 0$ and (2) 10-d protocol $(\mathrm{n}=991 ; 10 \mathrm{D})$ with 2 CIDR and $2.0 \mathrm{mg}$ of estradiol benzoate on $\mathrm{d}-12 ; 25 \mathrm{mg}$ of $\mathrm{PG}$ and withdrawal of 1 CIDR on $\mathrm{d}-4 ; 1.0 \mathrm{mg}$ of estradiol, second CIDR withdrawal, and PG on $\mathrm{d}-2$; and TAI on $\mathrm{d} 0$. There was no effect of protocol on estrus detection, whereas a greater percentage of cows from 10D had ovulated close to TAI [no corpus luteum (CL) at AI and a CL at d 7] versus cows assigned to 9D protocol. A protocol $\times$ heat stress (average cow temperature $\geq 39.1^{\circ} \mathrm{C}$ on day of $\mathrm{AI}$ and $\mathrm{d} 7$ ) interaction was observed in a manner that pregnancy per $\mathrm{AI}(\mathrm{P} / \mathrm{AI})$ was greater in non-heat-stressed $10 \mathrm{D}$ versus $9 \mathrm{D}$ cows, whereas $\mathrm{P} /$ AI did not differ when cows were under heat stress. Furthermore, 10D protocol did not increase P/AI when all cows that received AI were included in the analysis or in cows that ovulated near TAI. However, animals assigned to 9D without any event of heat stress had a reduced $\mathrm{P} / \mathrm{AI}$ when compared with cows assigned to $10 \mathrm{D}$ without heat stress. A protocol $\times$ CL presence at

\footnotetext{
Received May 10, 2020.

Accepted August 17, 2020.

*Corresponding author: jose.vasconcelos@unesp.br
}

the beginning of the protocol interaction was observed and cows with a CL at the beginning of the protocol had a greater $\mathrm{P} / \mathrm{AI}$ in $10 \mathrm{D}$ versus $9 \mathrm{D}$; meanwhile, in cows without a CL, no differences on $\mathrm{P} / \mathrm{AI}$ were observed. The protocol $\times$ CL presence at the beginning of the protocol interaction on $\mathrm{P} / \mathrm{AI}$ was also observed for cows that ovulated near TAI. A greater percentage of cows assigned to 9D had follicles of medium size $(13-15.9 \mathrm{~mm})$, and greater percentage of cows assigned to 10D had larger follicles ( $>16 \mathrm{~mm})$. Increasing the length of an estradiol with progesterone-based ovulation synchronization protocol (10D vs. 9D) increased the proportion of cows with larger follicles $(>16 \mathrm{~mm})$ and increased $\mathrm{P} / \mathrm{AI}$ in cows without heat stress and in cows with a CL at beginning of the protocol. Moreover, the 10D protocol increased the proportion of cows with ovulation near TAI, demonstrating the effectiveness of this protocol in improving the reproductive performance of lactating Holstein cows.

Key words: dairy cows, fertility, artificial insemination, synchronization

\section{INTRODUCTION}

Several studies have evaluated the effect of altering the time from initiation of corpus luteum (CL) regression before timed AI (TAI) or the length of protocols on pregnancy per AI (P/AI) during ovulation synchronization protocols in dairy cattle (Peters and Pursley, 2003; Ribeiro et al., 2012; Pereira et al., 2013a). These alterations regarding protocol length and time of prostaglandin $\mathrm{F} 2 \alpha(\mathbf{P G})$ administration during ovulation synchronization protocols are associated with higher P/AI (Peters and Pursley, 2003; Ribeiro et al., 2012; Pereira et al., 2013a) and reduced pregnancy loss between 30 and $60 \mathrm{~d}$ of pregnancy (Pereira et al., 2014). Furthermore, there are effects of increased circulating progesterone $(\mathbf{P} 4)$ concentrations before $\mathrm{AI}$ on $\mathrm{P} / \mathrm{AI}$ 
(Pereira et al., 2017b, 2020; Wiltbank et al., 2014). Recent studies suggest that cows ovulating larger follicles in estradiol with progesterone (E2/P4)-based ovulation synchronization protocols with a CL (Pereira et al., 2013b) or higher circulating P4 concentrations (Monteiro et al., 2015; Melo et al., 2016; Pereira et al., 2017a,b, 2020) at PG administration had greater P/AI.

The time from initiation of CL regression until TAI was evaluated in E2/P4 protocols (Pereira et al., 2013a) in a manner that an earlier PG treatment (3 vs. $2 \mathrm{~d}$ before $\mathrm{AI}$ ) reduced circulating $\mathrm{P} 4$ concentrations at TAI and increased P/AI in both TAI and timed embryo transfer protocols in dairy cows. Benefits were also observed in synchronization protocols in beef (Meneghetti et al., 2009; Peres et al., 2009; Bridges et al., 2010) and dairy cattle submitted to Ovsynch protocols (Peters and Pursley, 2003; Ribeiro et al., 2012). Improvements on $\mathrm{P} / \mathrm{AI}$ resulting from an extended time period between induction of luteolysis and TAI could be related to an increased time for CL regression and reduced circulating $\mathrm{P} 4$ concentrations at TAI, or to a longer period of follicle growth, as well as increased ovulatory follicle size and estradiol (E2) concentrations before ovulation (Pereira et al., 2013a). Furthermore, benefits of lower circulating P4 concentrations at TAI and greater expression of estrus can be achieved through an increased protocol length. In E2/P4-based protocols, increasing protocol length ( 8 vs. 9 d) increased the percentage of cows detected in estrus and decreased pregnancy loss (Pereira et al., 2014), whereas increasing the timeinterval of PG treatment before TAI ( 2 vs. $3 \mathrm{~d}$ ) reduced circulating P4 concentrations at TAI (Pereira et al., 2013a).

Various strategies have been used during ovulation synchronization protocols to increase circulating $\mathrm{P} 4$ concentrations at PG, such as the addition of GnRH treatment at the beginning of the protocol (Pereira et al., 2015; Melo et al., 2016), the use of 2 P4 intravaginal devices (Bisinotto et al., 2013; Pereira et al., 2017a,b), and presynchronization protocols (Souza et al., 2008; Pereira et al., 2020). First, treatment with GnRH at the beginning of an E2/P4 ovulation synchronization protocol increased $\mathrm{P} / \mathrm{AI}$ compared with GnRH-untreated cows (Pereira et al., 2015). Furthermore, GnRH administration did not affect $\mathrm{P} / \mathrm{AI}$ or pregnancy loss when compared with $2 \mathrm{P} 4$ device protocols (Pereira et al., 2017b). Nonetheless, the percentage of cows in each protocol that had greater $\mathrm{P} 4$ concentrations than the threshold value used to predict $\mathrm{P} / \mathrm{AI}$ was similar when compared with the aforementioned control treatments (Pereira et al., 2017b). Pereira et al. (2017a) compared the use of 2 or 1 intravaginal $\mathrm{P} 4$ devices in cows without CL and low P4 concentrations at the beginning of the ovulation synchronization. They reported no protocol effect on $\mathrm{P} / \mathrm{AI}$ of cows with small follicles, whereas the 2-P4 device protocol improved $\mathrm{P} / \mathrm{AI}$ on cows with larger follicles at TAI. Similarly, in another study, Pereira et al. (2015) observed that cows synchronized with an E2/P4 protocol and with a CL at PG administration had greater $\mathrm{P} / \mathrm{AI}$ as ovulatory follicle diameter increased, but no effect was observed in cows without a CL. Therefore, it might be possible that in protocols that increase circulating $\mathrm{P} 4$ concentrations during follicular development, benefits on P/AI may be achieved through an increase in follicle diameter.

Based on this rationale, we hypothesized that increasing the length of an E2/P4-based ovulation synchronization protocol with 2-P4 devices would result in greater P4 concentrations during follicular development, ovulation of a larger follicle, and an increased $\mathrm{P} / \mathrm{AI}$ of lactating dairy cows. Therefore, the objective of this study was to compare the effects of different lengths of ovulation synchronization protocols using 2 $\mathrm{P} 4$ devices on $\mathrm{P} / \mathrm{AI}$ variables of lactating dairy cows. An additional objective of the present study was to evaluate the possible interactions of environment (heat stress) and lactation status (milk production and DIM) with the protocols used herein on reproductive function of dairy cows.

\section{MATERIALS AND METHODS}

This experiment was conducted in 2 commercial dairy farms located in Minas Gerais State, Brazil, from January to October 2014. All animal procedures followed the recommendations of the Guide for the Care and Use of Agricultural Animals in Agricultural Research and Teaching (FASS, 2010).

During the experimental period, cows were housed in freestall barns with access to an adjoining sod-based paddock. Throughout the experiment and in both farms enrolled herein, cows were milked 3 times daily. All procedures, treatments, ovarian ultrasonography, pregnancy diagnosis, blood collection, and TAI, were performed while cows were restrained in self-locking stanchions at the feedbunk. Cows had ad libitum access to a TMR based on corn silage and Tifton- 85 hay (Cynodon dactylon) as forage sources and a concentrate composed of corn, soybean meal, minerals, and vitamins. The TMR was balanced to meet or exceed the nutritional requirements of lactating dairy cows (NRC, 2001).

\section{Animals and Treatments}

This study used a total of 1,979 lactating Holstein cows, and at the beginning of the experiment, cows averaged $153 \pm 2.5$ DIM, milk yield of $26 \pm 0.18 \mathrm{~kg} /$ 
day, BCS of $2.9 \pm 0.01$ (using a 1-5 scale, where $1=$ emaciated and $5=$ obese; Wildman et al., 1982), and lactation number of $2.78 \pm 0.04$ (487 primiparous and 1,492 multiparous). All animals had been previously bred $2.62 \pm 0.07$ times.

Within each farm, cows were blocked by parity (primiparous and multiparous), and all animals that were past the voluntary waiting period $(60 \mathrm{~d})$ and had been diagnosed as nonpregnant were enrolled in the study. Within each block, cows were randomly assigned to receive 1 of 2 protocols (Figure 1): (1) 9-d protocol $(\mathrm{n}=988 ; 9 \mathrm{D})$ with 2 controlled internal drug release (CIDR) intravaginal P4 devices containing $1.9 \mathrm{~g}$ of P4 (Zoetis, São Paulo, Brazil) and $2.0 \mathrm{mg}$ (i.m.) of estradiol benzoate (EB; $2.0 \mathrm{~mL}$ of Estrogin, Farmavet, São Paulo, Brazil) on d -11; 25 mg (i.m.) of dinoprost tromethamine (PG; $5.0 \mathrm{~mL}$ of Lutalyse, Zoetis) and withdrawal of 1 CIDR on $\mathrm{d}-4 ; 1.0 \mathrm{mg}$ (i.m.) of estradiol cypionate (ECP; $0.5 \mathrm{~mL}$, Zoetis), second CIDR withdrawal, and PG on $\mathrm{d}-2$; and TAI on $\mathrm{d} 0$ and (2) $10-\mathrm{d}$ protocol $(\mathrm{n}=991 ; 10 \mathrm{D})$ with 2 CIDR and 2.0 $\mathrm{mg}$ of $\mathrm{EB}$ on $\mathrm{d}-12 ; 25 \mathrm{mg}$ of $\mathrm{PG}$ and withdrawal of 1 CIDR on d $-4,1.0 \mathrm{mg}$ of ECP, second CIDR withdrawal, and PG on $\mathrm{d}-2$; and TAI on $\mathrm{d} 0$.

The TAI was performed (d 0) using commercial conventional frozen-thawed semen from 14 different bulls, and bulls were equally distributed among protocols. Estrus detection patches (Estrotect, Rockway, Inc., Spring Valley, WI) were placed on the tail head of cows at the time of the second CIDR withdrawal $(\mathrm{d}-2)$. The
Estrotect patches were not used for detection of estrus or timing of AI because all cows were bred to TAI by study personnel during the experimental period. Moreover, the Estrotect was scored at TAI by the research personnel, and cows with $\geq 50 \%$ activated patch were considered as expressing estrus between $\mathrm{d}-2$ and 0 of the protocol (Franco et al., 2018).

\section{Ultrasonography}

Regardless of protocol assignment, ovaries were evaluated by transrectal ultrasonography (SSD-500 with a 7.5-MHz linear-array transducer, Aloka, Tokyo, Japan) on $\mathrm{d}-12,-4$, and 7 to determine the presence of a CL and to measure the diameter of the largest follicle on d 0. Pregnancy diagnoses were performed by detection (transrectal ultrasonography) of a live embryo (presence of heartbeat) on d 32 post-TAI. Cows were assumed to have ovulated near TAI by the absence of a CL at TAI (d 0) and presence of a CL on d 7. Pregnancy per AI was calculated by dividing the number of pregnant cows on $\mathrm{d} 32$ by the number of cows that were inseminated (TAI).

\section{Sample Collection}

Rectal temperature was measured in all cows using a digital thermometer (Jumbo Display Lab Thermometer; Delta Track, Pleasanton, CA) in the morning of d 0 and 7 (TAI and 7 d post-TAI, respectively). The

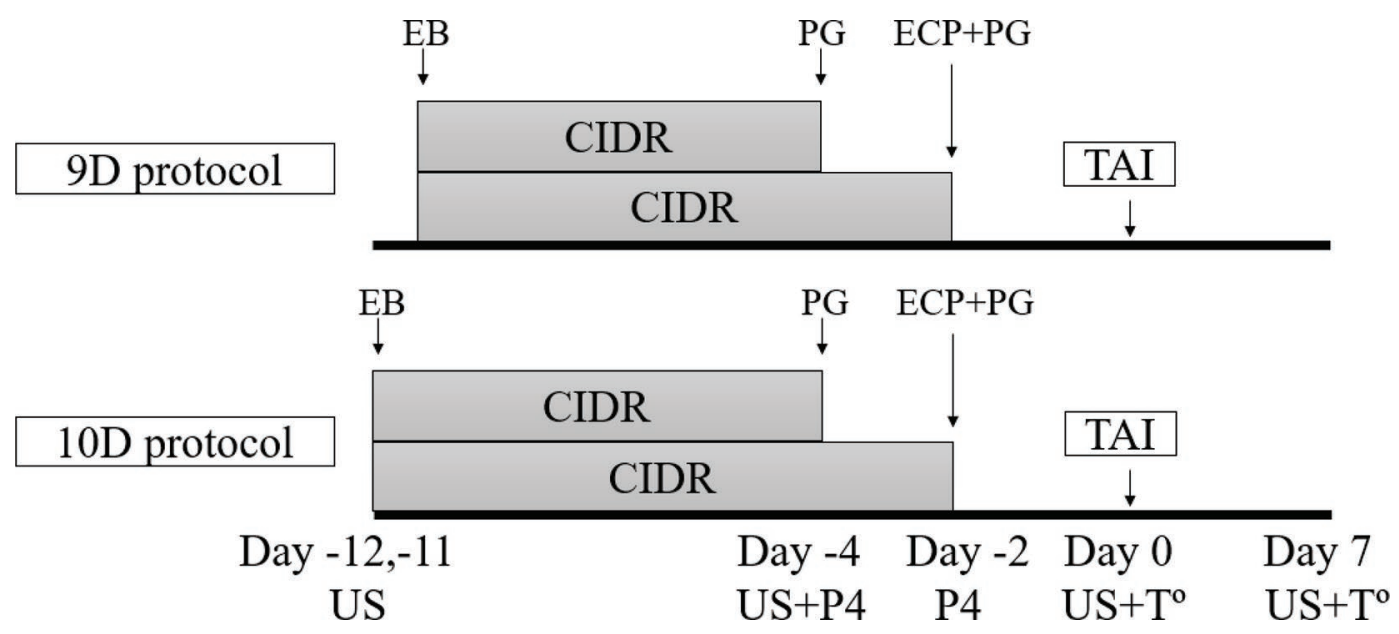

Figure 1. Schedule of activities performed in the present study: cows were randomly assigned to receive 1 of 2 protocols. (1) 9D protocol (n $=988)=2$ CIDR $+2.0 \mathrm{mg}$ of EB on $\mathrm{d}-11,25 \mathrm{mg}$ of PG, 1 CIDR withdrawal on $\mathrm{d}-4$, the other CIDR withdrawal, $1.0 \mathrm{mg}$ of ECP and PG on $\mathrm{d}-2$, and TAI on $\mathrm{d} 0 ;(2) 10 \mathrm{D}$ protocol $(\mathrm{n}=991)=2$ CIDR and $2.0 \mathrm{mg}$ of EB on $\mathrm{d}-12,25 \mathrm{mg}$ of PG and 1 CIDR withdrawal on d -4 , the other CIDR withdrawal, $1.0 \mathrm{mg}$ of ECP and PG on d -2 , and TAI on d 0 . P4 = blood sampling for determination of circulating progesterone concentrations (samples obtained on $\mathrm{d}-4$ and -2 ); US $=$ ovarian ultrasonography (days $-12,-4,0$, and 7 ); $\mathrm{T}^{\circ} \mathrm{C}=$ rectal temperature evaluated on the morning of $\mathrm{d} 0$ and 7 ; TAI $=$ timed $\mathrm{AI} ; \mathrm{CIDR}=$ controlled internal drug release device; $\mathrm{EB}=$ estradiol benzoate; $\mathrm{ECP}=$ estradiol cypionate; $\mathrm{PG}=$ prostaglandin. 
average temperature from both days was used to categorize cows as not having or having heat stress. Heat stress was defined when the mean rectal temperature was $\geq 39.1^{\circ} \mathrm{C}$, a value considered as the threshold for heat stress in dairy cattle (Berman et al., 1985; West, 2003). Additionally, the temperature of the animals at the exact moment of temperature measurement was taken into consideration for an analysis that classified animals as having none, 1 , or 2 events in which rectal temperature was $\geq 39.1^{\circ} \mathrm{C}$.

Average milk yield between d 0 and 7 was used in the analysis of the present study. Blood samples (approximately $10 \mathrm{~mL})$ were collected on $\mathrm{d}-4(\mathrm{n}=1,175)$ and $-2(\mathrm{n}=1,177)$ by coccygeal venipuncture into evacuated blood collection tubes (Vacutainer, Becton Dickinson, Franklin Lakes, NJ). Following blood sample collection, tubes were immediately placed on ice, maintained at $4^{\circ} \mathrm{C}$ for $12 \mathrm{~h}$, and centrifuged at $1,500 \times$ $g$ for $15 \mathrm{~min}$ at room temperature for serum collection. Serum was stored at $-20^{\circ} \mathrm{C}$ for subsequent $\mathrm{P} 4$ analysis. Serum concentrations of P4 were quantified by RIA using a double antibody RIA kit (MP Biomedicals, Costa Mesa, CA) as previously validated (Pohler et al., 2016). The intra- and interassay coefficients of variation were 3.98 and $11.34 \%$, respectively.

\section{Statistical Analysis}

For all analyses, cow was used as the experimental unit, the experiment was analyzed as a completely randomized block design, and the Satterthwaite approximation was used to determine the denominator degrees of freedom for tests of fixed effects.

The binomial variables (ovulation near TAI, P/AI, presence or absence of a CL on $\mathrm{d}-12$ and -4 , occurrence of estrus from $\mathrm{d}-2$ to 0 ) were analyzed using the GLIMMIX procedures of SAS (version 9.4, SAS Institute Inc., Cary, NC). The initial model contained the following variables as fixed effects: protocol (9D vs. 10D), parity (primiparous vs. multiparous), milk yield ( $<27$ vs. $\geq 27 \mathrm{~kg} /$ day $), \operatorname{BCS}(<2.75$ vs. $\geq 2.75)$, heat stress $\left(<39.1\right.$ vs. $\left.\geq 39.1^{\circ} \mathrm{C}\right)$, and $\mathrm{CL}$ presence at the beginning of the protocol, as well as interactions between these variables. Fixed effects with $P>0.10$ were removed in a stepwise backward elimination process until only fixed effects with a $P \leq 0.10$ remained in the model, whereas protocol and parity were forced in all models.

Protocol differences in circulating $\mathrm{P} 4$ concentrations on $\mathrm{d}-4$ and -2 and follicular diameter were analyzed using the MIXED procedures of SAS. The model statement contained the effects of protocol, parity, and the interaction between protocol and parity as fixed effects. The GLM procedure of SAS was used to determine whether each individual measurement influenced P/ AI linearly, quadratically, or cubically. The LOGISTIC procedure of SAS was used to determine the intercept and slope(s) values according to maximum likelihood estimates from each significant continuous order effect, and the P/AI was determined. Logistic curves were constructed using the minimum and maximum values detected for each individual measurement.

Follicle measurements were performed in all animals that ovulated near TAI and data were analyzed using the PPROC MIXED of SAS. Additionally, a tercile analysis was performed to provide more information regarding the effects of treatments on follicle diameter. The cows were split in terciles based on results for P/AI that presented a quadratic effect on $\mathrm{P} / \mathrm{AI}[\leq 12.9 \mathrm{~mm}$ ( $\mathrm{n}=518$ cows $), 13.0-15.9 \mathrm{~mm}(\mathrm{n}=511)$, and $\geq 16.0$ $\mathrm{mm}(\mathrm{n}=509)]$ so that a similar number of animals would be in each category. For all continuous variables, results are expressed as least squares means \pm SEM. In all analyses, differences were considered significant when $P \leq 0.05$, and tendencies were denoted with $P$ values between 0.05 and 0.10 .

\section{RESULTS}

There were no differences between 9D and 10D protocols for lactation number (2.81 vs. $2.87 \pm 0.05 ; P=$ $0.40)$, DIM (152.6 vs. $154.4 \pm 3.6 ; P=0.72), \operatorname{BCS}(2.91$ vs. $2.88 \pm 0.02 ; P=0.23$ ), milk yield ( 25.7 vs. $26.1 \pm$ $0.25 \mathrm{~kg} / \mathrm{d} ; P=0.26)$, CL presence at the beginning of the protocol $[63.2 \%(624 / 988)$ vs. $65.6 \%(650 / 991) ; P$ $=0.26]$, and average cow temperature $\left(39.1\right.$ vs. $39.1^{\circ} \mathrm{C}$ $\left.\pm 0.01^{\circ} \mathrm{C} ; P=0.23\right)$.

\section{Overall Effects on P/AI}

Table 1 summarizes the effects of protocols on estrus detection, percentage of cows with ovulation near TAI, and $\mathrm{P} / \mathrm{AI}$ for lactating dairy cows assigned to $9 \mathrm{D}$ or $10 \mathrm{D}$ protocols. There was no effect of protocol $(P=$ 0.38 ) on estrus detection (Table 1 ), whereas a greater $(P=0.01)$ percentage of cows from 10D ovulated near

Table 1. Effect of 9-d (9D) or 10-d (10D) protocol on estrus detection, ovulation near timed (TAI), and pregnancy per AI (P/AI)

\begin{tabular}{lccc}
\hline & \multicolumn{2}{c}{ Protocol } \\
\cline { 2 - 3 } Item & $9 \mathrm{D}$ & $10 \mathrm{D}$ & \multirow{2}{*}{$P$-value } \\
\hline Estrus detection & $79.7(787 / 988)$ & $81.2(805 / 991)$ & 0.38 \\
Ovulation near TAI & $85.6(846 / 988)$ & $89.3(885 / 991)$ & 0.01 \\
P/AI on d 32 & $25.4(251 / 988)$ & $27.7(274 / 991)$ & 0.26 \\
P/AI on d 32 & $29.7(251 / 846)$ & $31.0(274 / 885)$ & 0.56 \\
\hline
\end{tabular}

${ }^{1}$ Includes only cows that ovulated near TAI (corpus luteum assessment via ultrasonography on $\mathrm{d} 7$ ). 
Table 2. Effect of 9-d (9D) or 10-d (10D) protocol and heat stress on percentage of cows with a corpus luteum (CL) at PG (PGF $2 \alpha)$, circulating progesterone (P4) concentration at $\mathrm{PGF}$ and at day -2 (second CIDR removal), follicle diameter at AI, estrus detection, and ovulation near timed AI (TAI)

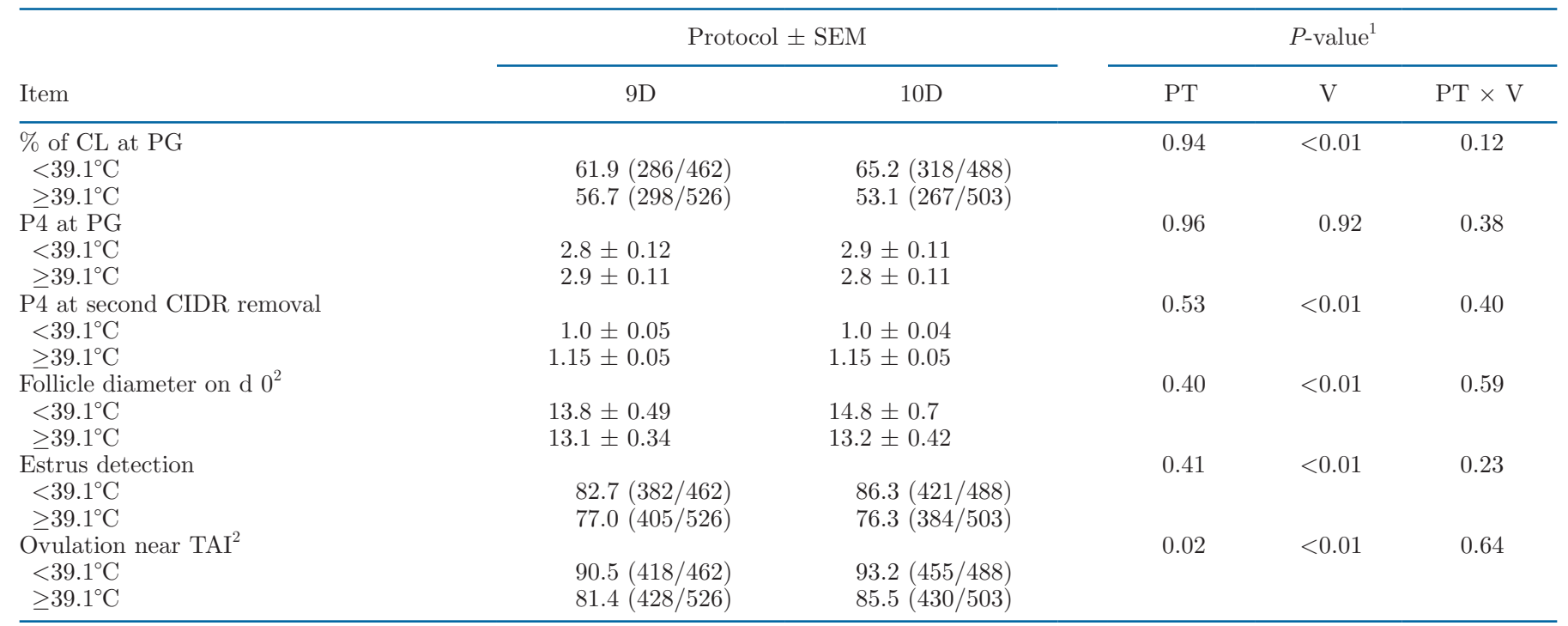

${ }^{1} \mathrm{PT}=$ protocol effect; $\mathrm{V}=$ variable effect $; \mathrm{PT} \times \mathrm{V}=$ protocol $\times$ variable interaction.

${ }^{2}$ Includes only cows that ovulated near TAI (visible CL on d 7).

TAI versus cows assigned to 9D. Furthermore, 10D protocol did not increase $\mathrm{P} / \mathrm{AI}(P=0.26)$ when all cows that received AI were included in the analysis or in cows that ovulated near TAI $(P=0.56)$.

In a subsequent analysis, the effects of protocol on $\mathrm{P} / \mathrm{AI}$ were stratified by heat stress, BCS, parity, milk yield, CL at the beginning of the protocol and on $\mathrm{d}$ -4 , and detection of estrus. There were no effects of protocol on $\mathrm{P} / \mathrm{AI}(P=0.26)$, and there were also no interactions for protocol by BCS $(P=0.85)$, parity $(P=0.63)$, milk yield $(P=0.56), \mathrm{CL}$ on $\mathrm{d}-4(P$ $=0.78)$, or detection of estrus $(P=0.23)$ on $\mathrm{P} / \mathrm{AI}$. Furthermore, regardless of protocol, there were effects of some variables on $\mathrm{P} / \mathrm{AI}$, such as the following: cows with lower BCS $[<2.75=21.6 \%(121 / 560)$ vs. $\geq 2.75=$ $28.5 \%$ (404/1419); $P<0.01]$, cows without a CL versus cows with a CL on $\mathrm{d}-4$ [no CL $=20.5 \%(166 / 810)$ vs. $\mathrm{CL}=30.7 \%(359 / 1169) ; P<0.01]$, and in cows with no detection of estrus [no estrus $=14.5 \%(56 / 387)$ vs. estrus $=29.5 \%(469 / 1592) ; P<0.01]$. Conversely, milk yield $(P=0.11)$ and parity $(P=0.63)$ did not affect $\mathrm{P} / \mathrm{AI}$.

\section{Effects of Protocols and Heat Stress on P/AI}

Heat stress altered reproductive physiology and decreased reproductive success in both protocols (Tables 2 and 3; Figures 2 and 3). Taking into consideration temperature evaluations on $\mathrm{d} 0$ and 7 , the percentage of cows with heat stress in the 2 protocols did not differ $[9 \mathrm{D}=53.2 \%(526 / 988)$ vs. $10 \mathrm{D}=50.8 \%(503 / 991) ; P$ $=0.27]$. A protocol $\times$ heat stress $(P=0.03)$ interaction was observed (Figure 2A), using cow temperature as a continuous variable, in a manner that $\mathrm{P} / \mathrm{AI}$ decreased as cow temperature increased in both protocols. Nonetheless, in cows without heat stress, P/AI was greater for $10 \mathrm{D}$ versus $9 \mathrm{D}$. Similar results were observed for cows that ovulated near TAI, considering that a proto$\mathrm{col} \times$ heat stress interaction tended to be observed $(P$ $=0.09 ;$ Figure $2 \mathrm{~B})$.

Table 3. Effect of 9-d (9D) or 10-d (10D) protocol on pregnancy per AI (P/AI) stratified by incidence of heat stress $\left(\geq 39.1^{\circ} \mathrm{C}\right)$

\begin{tabular}{|c|c|c|c|c|}
\hline \multirow[b]{2}{*}{$\mathrm{P} / \mathrm{AI}$ on $\mathrm{d} 32$} & \multicolumn{3}{|c|}{ Number of $\geq 39.1^{\circ} \mathrm{C}$ events } & \multirow[b]{2}{*}{$P$-value } \\
\hline & 0 & 1 & 2 & \\
\hline $9 \mathrm{D}$ & $30.2(95 / 315)^{\mathrm{a}}$ & $27.8(94 / 338)^{\mathrm{a}}$ & $18.5(62 / 335)^{\mathrm{b}}$ & $<0.01$ \\
\hline $10 \mathrm{D}$ & $37.4(126 / 337)^{\mathrm{a}}$ & $28.6(90 / 315)^{\mathrm{b}}$ & $17.1(58 / 339)^{c}$ & $<0.01$ \\
\hline$P$-value & 0.03 & 0.82 & 0.68 & \\
\hline
\end{tabular}

${ }^{\mathrm{a}-\mathrm{c}}$ Different superscript letters in the same line differ at $P<0.05$. 
When heat stress was analyzed in classes $(<39.1$ and $\geq 39.1^{\circ} \mathrm{C}$; Figure 3 ), cows without heat stress and assigned to $10 \mathrm{D}$ tended to have $(P=0.06)$ a greater $\mathrm{P} / \mathrm{AI}$ [35.5\% (173/488) vs. $27.7 \%(137 / 462)]$. Similar results were also observed for cows that ovulated near TAI [9D: $32.8 \%(137 / 418)$ vs. $10 \mathrm{D}: 38.0 \%(173 / 455) ; P=0.10]$. In cows with heat stress, no difference was observed for $\mathrm{P} / \mathrm{AI}$, independently of whether the analysis considered all cows [9D: $21.7 \%(114 / 526)$ vs. 10D: $20.1 \%$ $(101 / 503) ; P=0.53]$ or only those that ovulated near TAI [9D: $26.6(114 / 428)$ vs. 10D: $23.5 \%(101 / 430) ; P$ $=0.29$.

Table 2 reports the effect of heat stress on various parameters of reproductive physiology in cows assigned to the 2 protocols. There were no interactions between protocol $\times$ heat stress on the percentage of cows with CL $(P=0.12)$ and circulating $\mathrm{P} 4$ concentrations at PG
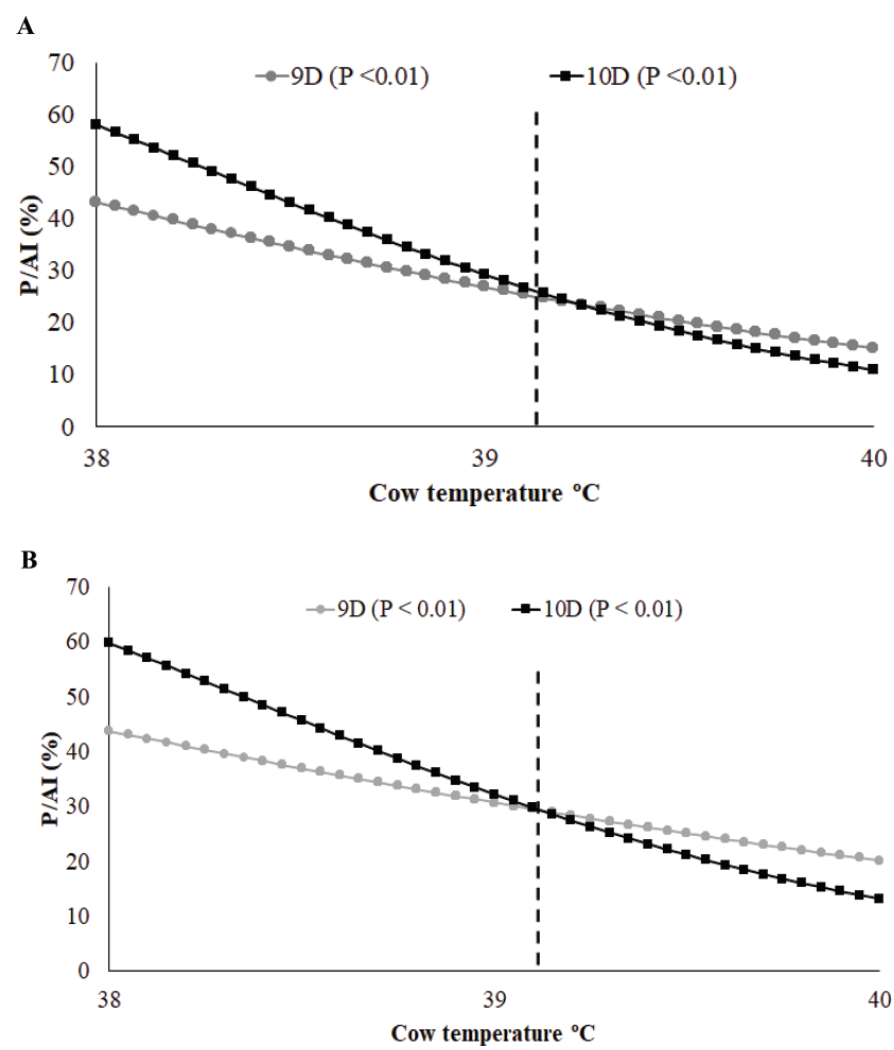

Figure 2. Logistic regression analysis of the relationship between heat stress and pregnancy per AI (P/AI) for cows that were assigned to protocols (9D and 10D; A) and ovulated near timed AI (TAI; B). A protocol $\times$ cow temperature $(P=0.03)$ interaction was observed herein. 9D protocol $(\mathrm{n}=988)=2 \mathrm{CIDR}+2.0 \mathrm{mg}$ of estradiol benzoate on $\mathrm{d}-11,25 \mathrm{mg}$ of $\mathrm{PG}, 1$ CIDR withdrawal on $\mathrm{d}-4$, the other CIDR withdrawal, $1.0 \mathrm{mg}$ of estradiol cypionate and prostaglandin on $\mathrm{d}-2$, and timed AI on d 0; (2) 10D protocol $(\mathrm{n}=991)=2$ CIDR and $2.0 \mathrm{mg}$ of estradiol benzoate on $\mathrm{d}-12,25 \mathrm{mg}$ of prostaglandin and 1 CIDR withdrawal on $\mathrm{d}-4$, the other CIDR withdrawal, $1.0 \mathrm{mg}$ of estradiol cypionate and PG on $\mathrm{d}-2$, and TAI on $\mathrm{d} 0$. CIDR $=$ controlled internal drug release device. administration $(P=0.38)$, at second CIDR removal $(P$ $=0.40)$, follicle diameter at AI $(P=0.59)$, estrus detection $(P=0.23)$, and ovulation near TAI $(P=0.64)$. Cows with greater rectal temperature had a reduced $(P$ $<0.01$ ) incidence of ovulation near TAI, and the 10D protocol resulted in a higher $(P=0.02)$ percentage of cows ovulating near TAI, regardless of heat stress $(P=$ $0.64)$. There was no effect of protocol on percentage of cows with $\mathrm{CL}$ at PG $(P=0.94)$, circulating $\mathrm{P} 4$ concentration at $\mathrm{PG}(P=0.96)$, circulating $\mathrm{P} 4$ concentration at second CIDR removal $(P=0.53)$, follicle diameter on d $0(P=0.40)$, and estrus detection $(P=0.41)$. Furthermore, heat stress affected some of the variables. The proportion $(P<0.01)$ of cows with $C L$ was higher

A
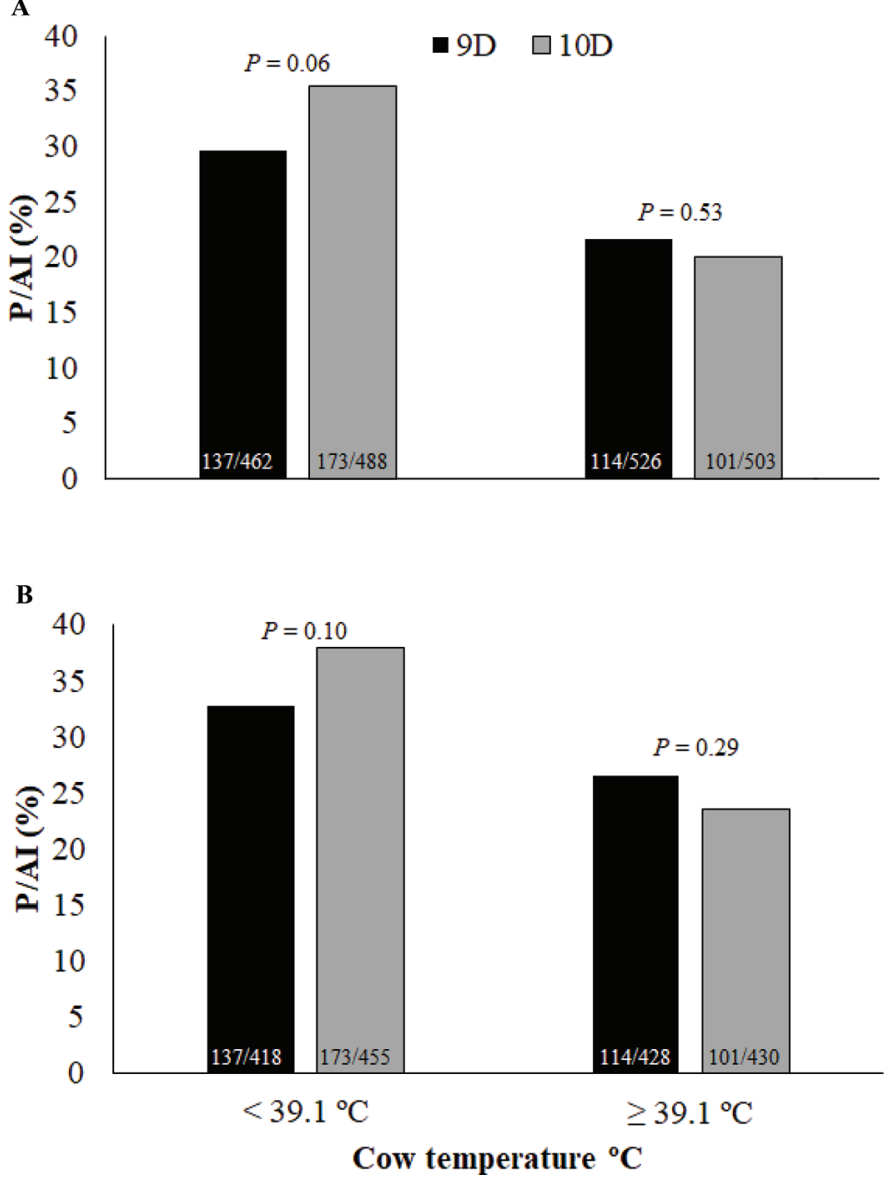

Figure 3. Pregnancy per AI (P/AI) for cows that were assigned to protocols (9D and 10D; A) and $\mathrm{P} / \mathrm{AI}$ for cows that were assigned to protocols (9D and 10D) and ovulated near timed AI (TAI; B). 9D protocol $(\mathrm{n}=988)=2$ CIDR $+2.0 \mathrm{mg}$ of estradiol benzoate on $\mathrm{d}-11$, $25 \mathrm{mg}$ of prostaglandin, 1 CIDR withdrawal on $\mathrm{d}-4$, the other CIDR withdrawal, $1.0 \mathrm{mg}$ of estradiol cypionate and prostaglandin on $\mathrm{d}-2$, and timed AI on d 0; (2) 10D protocol $(\mathrm{n}=991)=2$ CIDR and $2.0 \mathrm{mg}$ of estradiol benzoate on $\mathrm{d}-12,25 \mathrm{mg}$ of prostaglandin and 1 CIDR withdrawal on $\mathrm{d}-4$, the other CIDR withdrawal, $1.0 \mathrm{mg}$ of estradiol cypionate and prostaglandin on $\mathrm{d}-2$, and timed $\mathrm{AI}$ on $\mathrm{d}$ 0. CIDR $=$ controlled internal drug release device. 
Table 4. Effect of 9-d (9D) or 10-d (10D) protocol and corpus luteum (CL) presence at beginning of the protocol on circulating progesterone concentration at $\mathrm{PG}\left(\mathrm{PGF}_{2 \alpha}\right)$, follicle diameter at $\mathrm{AI}$, estrus detection, ovulation near timed $\mathrm{AI}(\mathrm{TAI})$, and pregnancy per AI (P/AI)

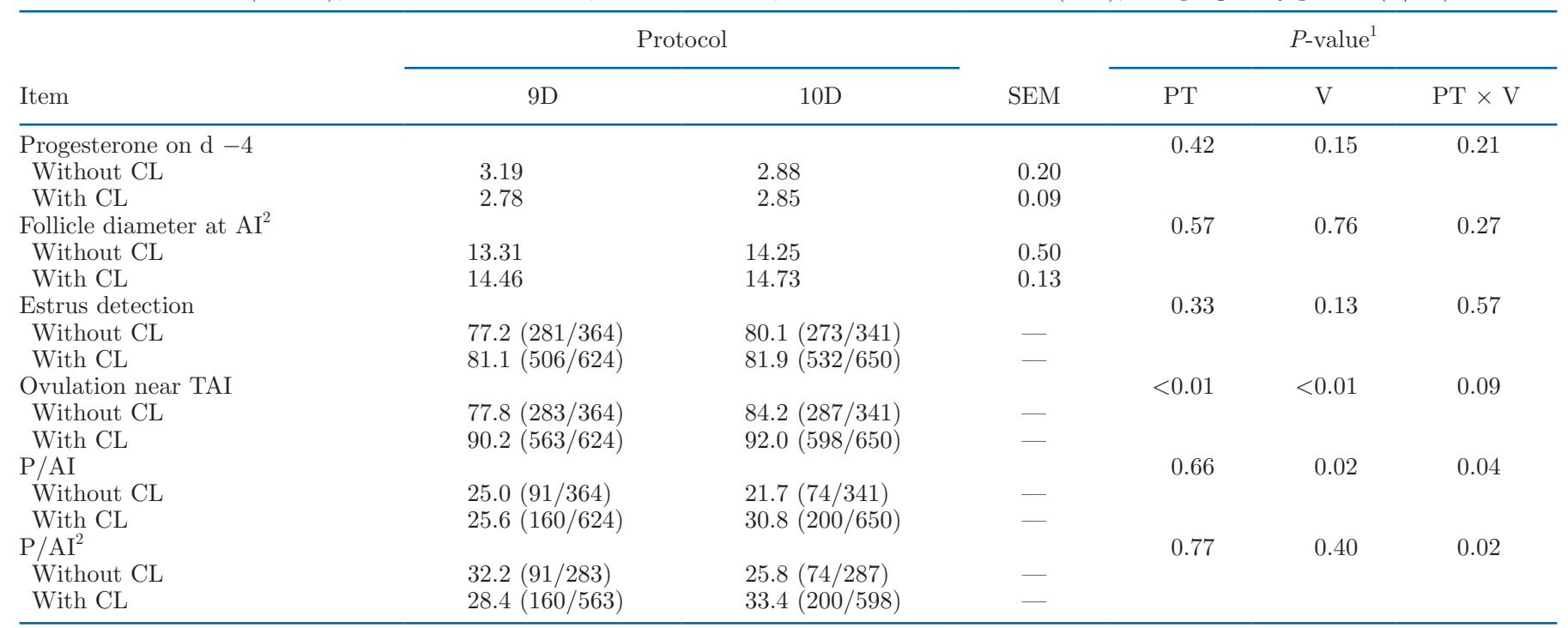

${ }^{1} \mathrm{PT}=$ protocol effect; $\mathrm{V}=$ variable effect; $\mathrm{PT} \times \mathrm{V}=$ protocol $\times$ variable interaction.

${ }^{2}$ Includes only cows that ovulated near TAI (visible CL on d 7).

on the day of PG administration in cows without versus with heat stress, but no differences were observed $(P$ $=0.92)$ on circulating $\mathrm{P} 4$ concentration at time of $\mathrm{PG}$ treatment $(\mathrm{d}-4)$. Moreover, cows without heat stress had reduced circulating $\mathrm{P} 4$ concentration when the second CIDR was removed $(P<0.01)$, larger follicles at AI $(P<0.01)$, and higher estrus detection rates $(P$ $<0.01)$ when compared with cows suffering from heat stress.

An additional analysis was performed to evaluate the effects of cows presenting heat stress on the moment of rectal temperature evaluation (Table 3 ). Cows without heat stress had greater $\mathrm{P} / \mathrm{AI}$ on the $10 \mathrm{D}$ versus $9 \mathrm{D}$ protocol $(P=0.03)$, whereas no further differences were observed among cows presenting $1(P=0.82)$ or 2 events $(P=0.68)$ of rectal temperature $\geq 39.1^{\circ} \mathrm{C}$ (Table $3)$.

\section{Effects of Protocol $\times$ CL Presence at Beginning of the Protocol}

Differences in P/AI due to protocol and CL presence at the beginning of the protocol are reported in Table 4. A protocol $\times$ CL presence at the beginning of the protocol interaction $(P=0.04)$ was observed, and cows with a CL at the beginning of the protocol had a greater $(P=0.04) \mathrm{P} / \mathrm{AI}$ in $10 \mathrm{D}$ vs. 9D. Conversely, no differences were observed on $\mathrm{P} / \mathrm{AI}$ in cows without a $\mathrm{CL}(P=0.32)$. The protocol $\times \mathrm{CL}$ at the beginning of the protocol interaction was also observed for cows that ovulated near TAI $(P=0.02)$, whereas no 3 -way interaction $(P=0.50)$ was detected between protocol $\times \mathrm{CL}$ at the beginning of the protocol $\times$ heat stress. Lastly, no protocol $\times$ CL at beginning of the protocol interactions were observed on circulating $\mathrm{P} 4$ concentration on $\mathrm{d}-4(P=0.21)$, follicle diameter at $\mathrm{AI}(P=$ $0.27)$, and detection of estrus $(P=0.57)$.

\section{Effects of Circulating P4 Concentration at PG and at CIDR Removal on PIAI}

Protocol did not have an effect $(P=0.96)$ on circulating $\mathrm{P} 4$ concentration on $\mathrm{d}-4$ ( $\mathrm{PG}$ administration; Table 2). An interaction was not detected between protocol $\times$ circulating $\mathrm{P} 4$ concentration on $\mathrm{P} / \mathrm{AI}(P=$ 0.35 ; Figure 4$)$; meanwhile, there was an effect of circulating $\mathrm{P} 4$ concentration at $\mathrm{PG}$ on $\mathrm{P} / \mathrm{AI}(P<0.01)$. We detected no interaction $(P=0.40)$ between protocol and heat stress on circulating $\mathrm{P} 4$ concentration at second CIDR removal. Both protocols had $(P=0.53)$ no effect on circulating P4 concentration at second CIDR removal, whereas cows with heat stress had greater $(P<0.01)$ circulating $\mathrm{P} 4$ concentration. Additionally, there was no effect of circulating $\mathrm{P} 4$ concentration at second CIDR removal on estrus detection $(P=0.11)$, ovulation near TAI $(P=0.61)$, and $\mathrm{P} / \mathrm{AI}(P=0.90)$.

\section{Effects of Estrus on P/AI}

There were no interactions between protocol and estrus expression on ovulation to ECP $(P=0.82)$ or $\mathrm{P} / \mathrm{AI}(P=0.58)$. Cows detected on estrus had greater 
ovulation rate near TAI [estrus $=93.5 \%(1489 / 1592)$ vs. no estrus $=62.5 \%(242 / 387) ; P<0.01]$ and $\mathrm{P} /$ AI [estrus $=29.5 \%(469 / 1592)$ vs. no estrus $=14.5 \%$ (56/387); $P<0.01]$ than cows not detected on estrus. The same effect on $\mathrm{P} / \mathrm{AI}$ was observed when only cows that ovulated near TAI were considered in the analysis [estrus $=31.5 \%(469 / 1489)$ vs. no estrus $=23.1 \%$ (56/242); $P<0.01]$. In cows assigned to both protocols, the probability of estrus increased $(P<0.01)$ as follicle diameter at AI increased (Figure $5 \mathrm{~A}$ ), whereas the probability of estrus decreased as circulating $\mathrm{P} 4$ concentration at $\mathrm{PG}$ increased for cows assigned to 9D protocol $(P<0.01)$ and tended to decrease for cows assigned to $10 \mathrm{D}(P=0.07$; Figure $5 \mathrm{~B})$.

\section{Effects of Ovulatory Follicle Diameter on P/AI}

Protocol length did not have an effect $(P=0.40)$ on ovulatory follicle diameter at TAI (Table 2). Although the percentage of cows with small $(<13 \mathrm{~mm})$ ovulatory follicles was similar between protocols $(P=0.74)$, a greater percentage of cows assigned to $9 \mathrm{D}$ had follicles of medium size $(13-15.9 \mathrm{~mm} ; P=0.02)$, and this response changed when larger follicles were compared $(>16 \mathrm{~mm} ; P=0.04 ;$ Figure $6 \mathrm{~A})$. Follicle diameter at TAI affected $(P<0.01) \mathrm{P} / \mathrm{AI}$ in cows that ovulated near TAI. Regardless of protocol, a reduced P/AI was observed in cows that ovulated too small or too large

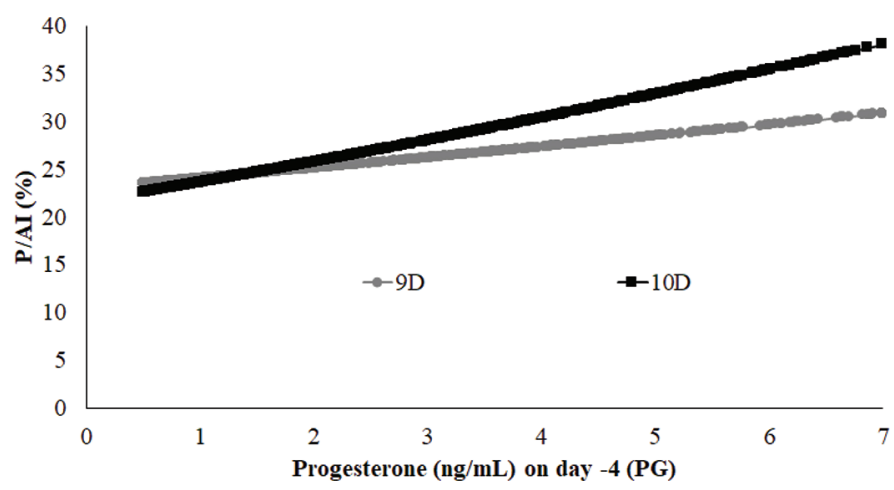

Figure 4. Logistic regression analysis of the relationship between circulating progesterone concentration on $\mathrm{d}-4$ and pregnancy per $\mathrm{AI}(\mathrm{P} / \mathrm{AI})$ on $\mathrm{d} 32$ for cows that were assigned to protocols (9D and 10D). A protocol $\times$ circulating progesterone concentration on $\mathrm{d}-4$ interaction was not observed herein $(P=0.35)$, but there was an effect of circulating progesterone concentration at prostaglandin $(\mathrm{PG})$ on $\mathrm{P} / \mathrm{AI}(P<0.01)$. 9D protocol $(\mathrm{n}=988)=2 \mathrm{CIDR}+2.0 \mathrm{mg}$ of estradiol benzoate on $\mathrm{d}-11,25 \mathrm{mg}$ of $\mathrm{PG}, 1 \mathrm{CIDR}$ withdrawal on $\mathrm{d}$ -4 , the other CIDR withdrawal, $1.0 \mathrm{mg}$ of estradiol cypionate and prostaglandin on $\mathrm{d}-2$, and timed AI on d $0 ;(2) 10 \mathrm{D}$ protocol $(\mathrm{n}=$ 991) $=2 \mathrm{CIDR}$ and $2.0 \mathrm{mg}$ of estradiol benzoate on $\mathrm{d}-12,25 \mathrm{mg}$ of prostaglandin and 1 CIDR withdrawal on $\mathrm{d}-4$, the other CIDR withdrawal, $1.0 \mathrm{mg}$ of estradiol cypionate and $\mathrm{PG}$ on $\mathrm{d}-2$, and timed $\mathrm{AI}$ on $\mathrm{d}$ 0. CIDR $=$ controlled internal drug release device.
A

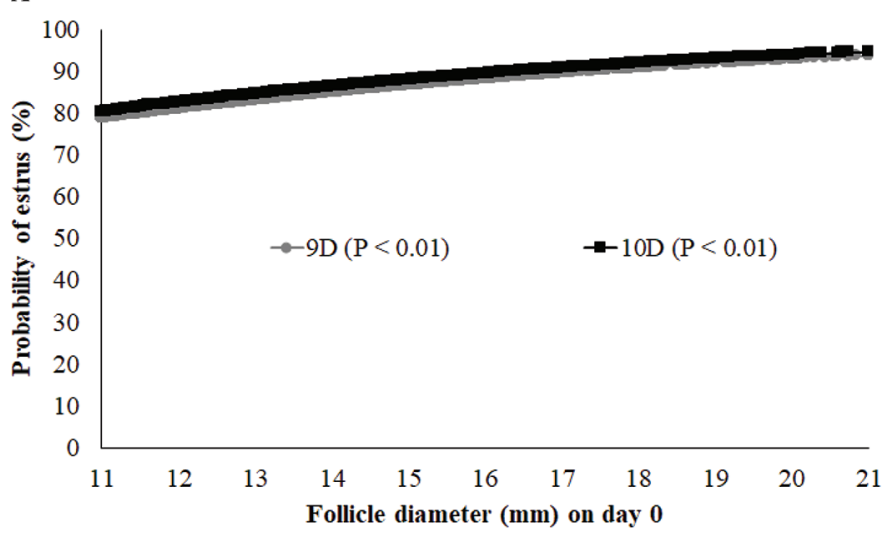

B

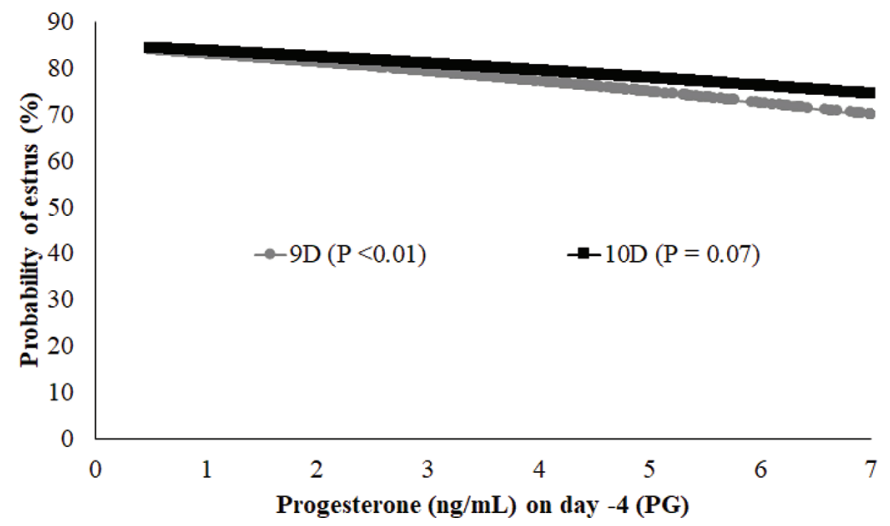

Figure 5. Logistic regression analysis of the relationship between follicle diameter on d 0 (A) and mean progesterone concentration on $\mathrm{d}$ -4 (B) in cows that ovulated near timed AI and probability of estrus for cows that were assigned to protocols (9D and 10D). 9D protocol $(\mathrm{n}=988)=2$ CIDR $+2.0 \mathrm{mg}$ of estradiol benzoate on $\mathrm{d}-11,25 \mathrm{mg}$ of prostaglandin, 1 CIDR withdrawal on $\mathrm{d}-4$, the other CIDR withdrawal, $1.0 \mathrm{mg}$ of estradiol cypionate and prostaglandin on $\mathrm{d}-2$, and timed AI on d 0; (2) 10D protocol $(\mathrm{n}=991)=2 \mathrm{CIDR}$ and $2.0 \mathrm{mg}$ of estradiol benzoate on $\mathrm{d}-12,25 \mathrm{mg}$ of prostaglandin and 1 CIDR withdrawal on $\mathrm{d}-4$, the other CIDR withdrawal, $1.0 \mathrm{mg}$ of estradiol cypionate and prostaglandin on $\mathrm{d}-2$, and timed $\mathrm{AI}$ on $\mathrm{d}$ 0. CIDR $=$ controlled internal drug release device.

follicles (quadratic effect; $P<0.01$ ), whereas the negative effect of larger follicles on $\mathrm{P} / \mathrm{AI}$ was less dramatic in cows assigned to $10 \mathrm{D}$ versus $9 \mathrm{D}$ (Figure 6B).

\section{DISCUSSION}

This study evaluated whether increasing the length of an ovulation synchronization protocol would increase $\mathrm{P} / \mathrm{AI}$ when $\mathrm{E} 2$ and $2 \mathrm{P} 4$ devices are used to synchronize the estrous cycle of lactating dairy cows. We hypothesized that increasing the length of time from CIDR insertion would increase follicle development, and thereby increase follicle diameter at the time of TAI. Moreover, the combination of a protocol with 
greater circulating P4 concentrations during follicular development, in addition to a larger follicle diameter, would improve P/AI. There was no detectable increase in follicle diameter, although the distribution of follicle sizes was altered. Also, the 10D protocol resulted in a greater ovulation near TAI than the 9D protocol. Our main hypothesis was that the longer protocol would result in a greater P/AI. Thus, increasing protocol length from 9 to $10 \mathrm{~d}$ had a positive effect, with increased ovulation near TAI and $\mathrm{P} / \mathrm{AI}$ in cows without heat stress. Additional analysis of 1,979 cows for individual ovarian, hormonal, and reproductive measures provided some important insights into potential future improvements that could be made in these protocols to improve the reproductive performance of lactating dairy cows.

The large number of cows used in this study was sufficient for both categories of heat stress [no heat stress $(\mathrm{n}=950)$ and with heat stress $(\mathrm{n}=1,029)]$ to allow analysis of heat stress effects on physiological measures

A

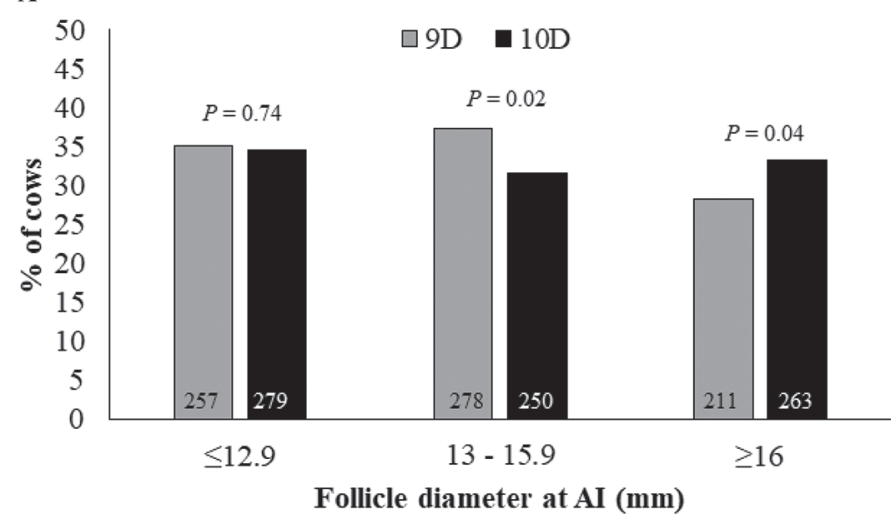

B

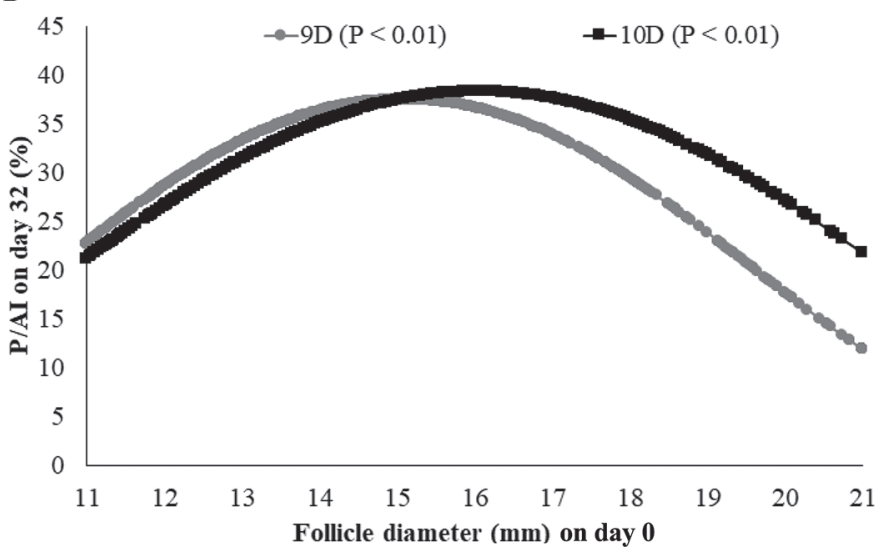

Figure 6. Percentage of cows within treatment presenting a small, medium, and large follicle diameter at AI (A) and logistic regression analysis of the relationship between follicle diameter on $\mathrm{d} 0$ and pregnancy per $\mathrm{AI}(\mathrm{P} / \mathrm{AI})$ on $\mathrm{d} 32$ for cows that were assigned to protocols (B). and protocol effects. This study directly used the rectal temperature of each individual cow near the time of AI based on the average of 2 independent observations (at TAI and $7 \mathrm{~d}$ post-AI), rather than only environmental temperature or temperature-humidity index, because cow temperature has been the most sensitive measure of negative effect of heat stress on P/AI (Vasconcelos et al., 2011; Pereira et al., 2015, 2017b). Heat stress is a critical factor that altered reproductive physiology and decreased reproductive success in both protocols, and was observed in $\sim 50 \%$ of cows during the experiment. The protocol $\times$ heat stress interaction observed demonstrated that cows submitted to $9 \mathrm{D}$ protocol without heat stress had a reduced $\mathrm{P} / \mathrm{AI}$ when compared with cows assigned to $10 \mathrm{D}$, whereas no differences between protocols was observed in cows with heat stress. Similar results were observed in a previous study (Pereira et al., 2015) designed to increase $\mathrm{P} / \mathrm{AI}$, in which the differences between protocols on P/AI was only apparent during the cool season. Also, in Pereira et al. (2015), physiological measurements generally associated with improved fertility were adversely affected during the warm season. More specifically, the percentage of cows with CL at PG decreased by $6.7 \%$, ovulatory follicle diameter decreased $0.9 \mathrm{~mm}$, expression of estrus decreased $6.8 \%$, and ovulation near TAI decreased $5.4 \%$. Similarly, in another study (Pereira et al., 2017b) evaluating heat stress by cow temperature, physiological measurements were also reduced in cows with heat stress, highlighting the negative effects that heat stress has on health and reproductive function of dairy cattle. In agreement with previous studies, cows with heat stress herein also had alterations in several physiological measurements, such as a reduction in the percentage of cows with CL at PG $(-8.7 \%)$, ovulatory follicle diameter $(-0.89 \mathrm{~mm})$, expression of estrus decreased $(-7.8 \%)$, and ovulation near TAI $(-8.5 \%)$. Previous studies have also reported that heat stress reduced follicular growth (Wilson et al., 1998), altered production of steroids by growing follicles (Wolfenson et al., 1995, 1997; Wilson et al., 1998), and reduced expression of estrus (Younas et al., 1993) and consequent ovulation (Pereira et al., 2013b). Each of these physiological changes could account for some decrease in fertility, but there are also negative effects of heat stress on $\mathrm{P} / \mathrm{AI}$ through a reduction in oocyte competence (Torres-Júnior et al., 2008; Rispoli et al., 2013), fertilization (Hackbart et al., 2010), early embryo development (Hansen and Aréchiga, 1999; Wolfenson et al., 2000; Hansen et al., 2001), and maintenance of pregnancy (Biggers et al., 1987; Ryan et al., 1993; Demetrio et al., 2007; Vasconcelos et al., 2011). Hence, it is imperative that dairy producers and researchers develop additional nutritional or management strate- 
gies that alleviate the negative effects of heat stress on reproductive function of dairy cattle.

Strategies that improve the size of the ovulatory follicle have been an important objective of the development of protocols to synchronize ovulation in dairy and beef cows (Perry et al., 2005; Souza et al., 2009; Pereira et al., 2013b;). In agreement with previous studies (Vasconcelos et al., 2001; Souza et al., 2007; Wiltbank et al., 2011a), P/AI in the present study was reduced for cows that ovulated smaller and larger follicles (quadratic effect). This effect of follicle diameter was detected regardless of which protocols cows were assigned to, but the negative effect of larger follicles on $\mathrm{P} / \mathrm{AI}$ was less dramatic in cows assigned to $10 \mathrm{D}$ versus $9 \mathrm{D}$. The use of $\mathrm{GnRH}$ to stimulate the ovulation of small follicles is often associated with a reduced $\mathrm{P} / \mathrm{AI}$, circulating E2 concentrations before TAI, circulating $\mathrm{P} 4$ concentrations after TAI, and increased percentage of cow that exhibit short luteal phases following TAI (Vasconcelos et al., 2001). In agreement with our results, the ovulation of smaller follicles upon the use of E2/P4-based protocols reduced estrus detection rate and circulating P4 concentration on $7 \mathrm{~d}$ after TAI, likely due to the presence of a smaller CL (Pereira et al., 2016). These latter authors did not observe an effect of the ovulation of a smaller follicle on pregnancy of embryo recipients, indicating that effects of a smaller follicle may be more evident on events before d 7 of pregnancy, such as follicular maturation, oocyte competence, ovulation, fertilization, early embryonic development, and gamete or embryo transport. In the current study, ovulation of a smaller follicle not only resulted in reduced detection of estrus and potentially decreased circulating E2 concentration, but also may have reduced $\mathrm{P} / \mathrm{AI}$ due to early pregnancy effects, perhaps related to reduced circulating P4 in the early luteal phase (Pereira et al., 2016).

Ovulation of larger follicles is generally associated with reduced P/AI because of excessive length of dominant follicle persistence (Townson et al., 2002; Bleach, Glencross and Knight, 2004; Cerri et al., 2009). Pereira et al. (2016) observed that in cows not showing estrus, larger follicles resulted in a linear reduction on pregnancy per embryo transfer, suggesting that effects of prolonged length of follicle dominance may have negative effects on the uterus by affecting pregnancy maintenance in embryo recipient. Although ovulation of a large follicle is associated with a reduced P/AI, it has also been associated with greater circulating P4 concentrations after TAI (Vasconcelos et al., 2001), which might improve P/AI (Demetrio et al., 2007; Wiltbank et al., 2011b; Forro et al., 2012). Interestingly, some previous studies have reported that larger follicles at
$\mathrm{AI}$ were associated with a greater $\mathrm{P} / \mathrm{AI}$, particularly in protocols that promote or sustain greater circulating $\mathrm{P} 4$ concentrations at $\mathrm{PG}$ administration (Pereira et al., 2013b, 2015, 2017a,b, 2020). Therefore, it may be expected that in cows ovulating a larger follicle that grew under an increased P4 environment, the negative effects of larger follicles may be alleviated. Pereira et al. (2015) observed that lactating dairy cows synchronized with an E2/P4 protocol and that had a CL at the time of $\mathrm{PG}$ administration had a greater $\mathrm{P} / \mathrm{AI}$ as ovulatory follicle diameter increased (linear effect), but this effect of follicle diameter was not observed in cows without a CL at PG treatment. Similarly, the same authors (Pereira et al., 2020) observed that when cows had a reduced $\mathrm{P} 4$ concentration at $\mathrm{PG}$ treatment, increasing the diameter of the ovulatory follicle had a negative effect on $\mathrm{P} / \mathrm{AI}$. These results suggest that the growth of a large follicle in an environment with a low circulating $\mathrm{P} 4$ concentration negatively affects $\mathrm{P} / \mathrm{AI}$, but does not alter or improve $\mathrm{P} / \mathrm{AI}$ if the emerging follicles are growing under an environment with a high circulating $\mathrm{P} 4$ concentration.

The circulating $\mathrm{P} 4$ concentrations on $\mathrm{d}-4$ of the protocol had a linear effect on $\mathrm{P} / \mathrm{AI}$. The effects of increased circulating $\mathrm{P} 4$ concentration before AI have been linked to reduced size of the preovulatory follicle, improved competence of the ovulated oocyte, and subsequent improvements in embryo quality during the first week of embryo development (Wiltbank et al., 2014). For example, Cerri et al. (2011a,b) collected embryos $6 \mathrm{~d}$ after AI in dairy cows submitted to protocols with low or high circulating P4 concentration, and reported no effect of $\mathrm{P} 4$ on fertilization rate, but a tendency for greater embryo quality in cows assigned to protocols that stimulated an elevated circulating $\mathrm{P} 4$ concentration environment during preovulatory follicle development. Similarly, Rivera et al. (2011) reported an increased proportion of transferrable embryos (78.6 vs. $55.9 \%$ ) when donors that were superovulated during the first follicular wave (low $\mathrm{P} 4$ ) received $2 \mathrm{P} 4$ devices during the protocol. The greater circulating P4 concentration seems to be more evident in the fertility of larger follicles; cows with reduced circulating P4 concentrations during follicle development had a greater number of LH pulses compared with cows with elevated circulating P4 concentration (Lucy et al., 1992; Bergfeld et al., 1996). This latter fact could be more detrimental to cows ovulating larger follicles, given that larger follicles have greater expression of $\mathrm{LH}$ receptors on granulosa cells (Xu et al., 1995; Ginther et al., 1996). In addition, a recent study from our research group (Dias and Vasconcelos, 2015) observed that reduced circulating $\mathrm{P} 4$ concentration can increase LH re- 
ceptor mRNA expression in granulosa cells of dominant follicles of Nellore heifers. Thus, an increased number of LH pulses and increased follicular responsiveness to LH could underlie an effect of reduced P4 concentrations on oocyte and embryo quality (Cerri et al., 2011a,b; Rivera et al., 2011). In previous studies using E2/P4 protocols (Pereira et al., 2013b, 2014, 2016), there was a bimodal effect of follicle size on $\mathrm{P} / \mathrm{AI}$; cows that ovulated smaller or larger follicles had a reduction in $\mathrm{P} /$ AI, whereas circulating $\mathrm{P} 4$ concentrations at $\mathrm{PG}$ were not evaluated in these studies. In the present study, the circulating $\mathrm{P} 4$ concentration was only important at PG administration $(\mathrm{d}-4)$, and not when the second CIDR device was removed $(\mathrm{d}-2)$, suggesting that the effects of greater circulating $\mathrm{P} 4$ concentration during the protocol is critical around the time of follicle divergence. One possible caveat of the present study is that due to the fact that a strategy to increase follicle diameter was evaluated, it is difficult to determine what is caused by longer protocol length versus actual differences in follicle growth. The less marked reduction in $\mathrm{P} / \mathrm{AI}$ observed in cows that had larger follicles $(>16 \mathrm{~mm})$ assigned to 10D demonstrated that an additional day of protocol duration might have helped to improve P/AI in cows with larger follicles, which is important because of the large proportion of cows observed in this follicle class (approximately $30 \%$ of the cows).

In the present study, overall estrus detection rate was $>80 \%$, even in cows that ovulated small follicles and increased as follicle diameter increased. Our previous research demonstrated that cows induced to ovulate with ECP had greater estrus detection than cows induced to ovulate with GnRH (Pereira et al., 2013b). This is an advantage of ECP protocols because estrus detection is a predictor of higher $\mathrm{P} / \mathrm{AI}$ and reduced pregnancy loss (Pereira et al., 2013b, 2014, 2016). In addition to ECP treatment, increasing protocol length resulted in a greater estrus detection when 8 versus 9-d protocols were compared, likely due to greater endogenous E2 production or reduced circulating $\mathrm{P} 4$ concentration near TAI. The longer duration protocol would also allow an extended period of time for follicle growth, possibly increasing circulating E2 concentration, allowing greater time for CL regression, and reducing circulating P4 concentration (Pereira et al., 2013a). In the present study, there was no effect of the protocol in the percentage of cows detected in estrus, but it was consistent with previous observations of improved $\mathrm{P} / \mathrm{AI}$ in cows showing estrus during TAI protocols (Pereira et al., 2013b, 2014, 2016). In ovariectomized beef cattle, Roberts et al. (2012) hypothesized that preovulatory estradiol surge would be important for embryo survival and pregnancy establishment. Indeed, no exogenous E2 administration in the preovulatory period resulted in a similar pregnancy rate until d 19, but pregnancy rates on d 29 were reduced compared with cows that received either ECP or EB to increase circulating E2 during the preovulatory period (Roberts et al., 2012). It has been reported that an insufficient E2 threshold near TAI may alter the uterine gene and protein expression, resulting in an environment that is less adequate and suitable for maintenance of pregnancy (Miller et al., 1977; Bartol et al., 1981; Buhi, 2002). Additionally, it could be speculated that there could be a greater sensitivity of the uterine environment in a lactating dairy cow to the preovulatory effects of E2. In our study, ECP was administered as a strategy to synchronize time of ovulation and increase circulating E2 in the preovulatory period. However, additional E2 from the follicle might be required to result in estrus occurrence and in an optimal uterine environment to optimize reproductive function of lactating dairy females. Alternatively, it could be speculated that a greater period for follicle development may potentially improve pregnancy by enhancing the uterine environment. An interesting result observed herein is that probability of estrus decreased as circulating $\mathrm{P} 4$ concentration at PG increased, as the strategy to increase circulating $\mathrm{P} 4$ concentration, and consequently increase $\mathrm{P} / \mathrm{AI}$, can reduce estrus expression that is also associated with higher P/AI. The reduced estrus expression of cows with higher circulating $\mathrm{P} 4$ concentrations might be related to a lower expression of mRNA expression of LH receptor in granulosa cells (Dias and Vasconcelos, 2015). These results demonstrate the importance of increasing the length of protocols if the overall goal is to have a greater circulating $\mathrm{P} 4$ concentration during the period of follicular development.

Another intriguing observation herein was the improvements in $\mathrm{P} / \mathrm{AI}$ for cows assigned to $10 \mathrm{D}$ that had a CL at the beginning of the protocol. It was expected that the presence of a CL at beginning of the protocol would increase circulating $\mathrm{P} 4$ concentration during follicle development, but there was no difference in circulating $\mathrm{P} 4$ concentration at $\mathrm{PG}$ due to the presence or absence of a CL at the beginning of the protocol. This factor may occur because the CL regressed in some animals before PG administration (Pereira et al., 2020), whereas some cows may ovulate at a closer timeframe to the beginning of the protocol (Pereira et al., 2015, 2017a, 2020) and by the use of 2 P4 devices that allow for a better hormonal profile during protocol (Pereira et al., 2017a,b). These results suggest that the benefits of the presence of a CL at the beginning of the protocol are not only associated with P4 at PG. Additionally, the authors speculate that cows with a CL at the begin- 
ning of the protocol may have a better synchronization of the follicle emergence, which is associated with a better fertility in lactating dairy cows.

In summary, increasing the length of an E2/P4based ovulation synchronization protocol (10D vs. 9D) increased the proportion of cows with ovulation near TAI, the proportion of cows with larger follicles $(>16$ $\mathrm{mm}$ ), and $\mathrm{P} / \mathrm{AI}$ in cows without heat stress and in cows with a CL at beginning of the protocol.

\section{ACKNOWLEDGMENTS}

We acknowledge Coordenação de Aperfeiçoamento de Pessoal de Nível Superior (CAPES; Brasília, DF, Brazil) for supporting Marcos Henrique Colombo Pereira (grant number 88882.317784/2019-01) and the owners and staff of collaborating dairies for the use of their cows and facilities. The authors state that there were no conflicts of interest herein.

\section{REFERENCES}

Bartol, F. F., W. W. Thatcher, G. S. Lewis, E. L. Bliss, M. Drost, and F. W. Bazer. 1981. Effect of estradiol-17beta on PGF and total protein content in bovine uterine flushings and peripheral plasma concentration of 13, 14-dihydro-15-keto-PGF(2alpha). Theriogenology 15:345-358. https://doi.org/10.1016/0093-691X(81)90002-9.

Bergfeld, E. G., F. N. Kojima, A. S. Cupp, M. E. Wehrman, K. E. Peters, V. Mariscal, T. Sanchez, and J. E. Kinder. 1996. Changing dose of progesterone results in sudden changes in frequency of luteinizing hormone pulses and secretion of 17 beta-estradiol in bovine females. Biol. Reprod. 54:546-553. https://doi.org/10 .1095 /biolreprod54.3.546.

Berman, A., Y. Folman, M. Kaim, M. Mamen, Z. Herz, D. Wolfenson, A. Arieli, and Y. Graber. 1985. Upper critical temperatures and forced ventilation effects for high-yielding dairy cows in a subtropical climate. J. Dairy Sci. 68:1488-1495. https://doi.org/10.3168/ jds.S0022-0302(85)80987-5.

Biggers, B. G., R. D. Geisert, R. P. Wetteman, and D. S. Buchanan. 1987. Effect of heat stress on early embryonic development in the beef cow. J. Anim. Sci. 64:1512-1518. https://doi.org/10.2527/ jas1987.6451512x.

Bisinotto, R. S., E. S. Ribeiro, F. S. Lima, N. Martinez, L. F. Greco, L. F. Barbosa, P. P. Bueno, L. F. Scagion, W. W. Thatcher, and J. E. Santos. 2013. Targeted progesterone supplementation improves fertility in lactating dairy cows without a corpus luteum at the initiation of the timed artificial insemination protocol. J. Dairy Sci. 96:2214-2225. https://doi.org/10.3168/jds.2012-6038.

Bleach, E. C., R. G. Glencross, and P. G. Knight. 2004. Association between ovarian follicle development and pregnancy rates in dairy cows undergoing spontaneous oestrous cycles. Reproduction 127:621-629. https://doi.org/10.1530/rep.1.00190.

Bridges, G. A., M. L. Mussard, C. R. Burke, and M. L. Day. 2010 Influence of the length of proestrus on fertility and endocrine function in female cattle. Anim. Reprod. Sci. 117:208-215. https://doi .org/10.1016/j.anireprosci.2009.05.002.

Buhi, W. C. 2002. Characterization and biological roles of oviductspecific, oestrogen-dependent glycoprotein. Reproduction 123:355362. https://doi.org/10.1530/rep.0.1230355.

Cerri, R. L., R. C. Chebel, F. Rivera, C. D. Narciso, R. A. Oliveira, M. Amstalden, G. M. Baez-Sandoval, L. J. Oliveira, W. W. Thatcher, and J. E. P. Santos. 2011a. Concentration of progesterone during the development of the ovulatory follicle: II. Ovarian and uterine responses. J. Dairy Sci. 94:3352-3365. https://doi.org/10.3168/jds .2010-3735.

Cerri, R. L., R. C. Chebel, F. Rivera, C. D. Narciso, R. A. Oliveira, W. W. Thatcher, and J. E. Santos. 2011b. Concentration of progesterone during the development of the ovulatory follicle: I. Ovarian and embryonic responses. J. Dairy Sci. 94:3342-3351. https://doi .org/10.3168/jds.2010-3734.

Cerri, R. L., H. M. Rutigliano, R. C. Chebel, and J. E. Santos. 2009. Period of dominance of the ovulatory follicle influences embryo quality in lactating dairy cows. Reproduction 137:813-823. https:/ /doi.org/10.1530/REP-08-0242.

Demetrio, D. G., R. M. Santos, C. G. Demetrio, and J. L. Vasconcelos. 2007. Factors affecting conception rates following artificial insemination or embryo transfer in lactating Holstein cows. J. Dairy Sci. 90:5073-5082. https://doi.org/10.3168/jds.2007-0223.

Dias, H. P., and J. L. M. Vasconcelos. 2015. Effect of progesterone on the expression of mRNA of LH receptor and steroidogenic enzymes that regulate follicular development in granulosa cells of Nellore heifers. MS Thesis. Department of Animal Production, Universidade Estadual Paulista, Botucatu/SP.

FASS. 2010. Chapter 7: Dairy Cattle. Accessed Sept. 9, 2020. https:/ /www.adsa.org/Portals/_default/SiteContent/docs/AgGuide3rd/ Chapter07.pdf.

Forro, A., G. Tsousis, N. Beindorff, R. Sharifi, L. Jäkel, and H. Bollwein. 2012. Combined use of Ovsynch and progesterone supplementation after artificial insemination in dairy cattle. J. Dairy Sci. 95:4372-4381. https://doi.org/10.3168/jds.2011-5196.

Franco, G. A., R. F. Peres, C. Martins, S. T. Reese, J. L. M. Vasconcelos, and K. G. Pohler. 2018. Sire contribution to pregnancy loss and pregnancy-associated glycoprotein production in Nelore cows. J. Anim. Sci. 96:632-640. https://doi.org/10.1093/jas/sky015.

Ginther, O. J., M. C. Wiltbank, P. M. Fricke, J. R. Gibbons, and K. Kot. 1996. Selection of the dominant follicle in cattle. Biol. Reprod. 55:1187-1194. https://doi.org/10.1095/biolreprod55.6.1187.

Hackbart, K. S., R. M. Ferreira, A. A. Dietsche, M. T. Socha, R. D. Shaver, M. C. Wiltbank, and P. M. Fricke. 2010. Effect of dietary organic zinc, manganese, copper, and cobalt supplementation on milk production, follicular growth, embryo quality, and tissue mineral concentrations in dairy cows. J. Anim. Sci. 88:3856-3870. https://doi.org/10.2527/jas.2010-3055.

Hansen, P. J., and C. F. Aréchiga. 1999. Strategies for managing reproduction in the heat-stressed dairy cow. J. Anim. Sci. 77(Suppl 2):36-50. https://doi.org/10.2527/1997.77suppl_236x.

Hansen, P. J., M. Drost, R. M. Rivera, F. F. Paula-Lopes, Y. M. alKatanani, C. E. Krininger III, and C. C. Chase Jr.. 2001. Adverse impact of heat stress on embryo production: Causes and strategies for mitigation. Theriogenology 55:91-103. https://doi.org/10 .1016/S0093-691X(00)00448-9.

Lucy, M. C., J. D. Savio, L. Badinga, R. L. De La Sota, and W. W. Thatcher. 1992. Factors that affect ovarian follicular dynamics in cattle. J. Anim. Sci. 70:3615-3626. https://doi.org/10.2527/1992 $.70113615 x$.

Melo, L. F., P. L. J. Monteiro Jr., R. S. Surjus, J. N. Drum, W. C. Wiltbank, and R. Sartori. 2016. Progesterone-based fixed-time artificial insemination protocols for dairy cows: Gonadotropin-releasing hormone versus estradiol benzoate at initiation and estradiol cypionate versus estradiol benzoate at the end. J. Dairy Sci. 99:9227-9237. https://doi.org/10.3168/jds.2016-11220.

Meneghetti, M., O. G. Sá Filho, R. F. Peres, G. C. Lamb, and J. L. M. Vasconcelos. 2009. Fixed-time artificial insemination with estradiol and progesterone for Bos indicus cows I: basis for development of protocols. Theriogenology 72:179-189. https://doi.org/10.1016/ j.theriogenology.2009.02.010.

Miller, B. G., N. W. Moore, L. Murphy, and G. M. Stone. 1977. Early pregnancy in the ewe: Effects of oestradiol and progesterone on uterine metabolism and on embryo survival. Aust. J. Biol. Sci. 30:279-288. https://doi.org/10.1071/BI9770279.

Monteiro, P. L. Jr., M. Borsato, F. L. Silva, A. B. Prata, M. C. Wiltbank, and R. Sartori. 2015. Increasing estradiol benzoate, pretreatment with gonadotropin-releasing hormone, and impediments for 
successful estradiol-based fixed-time artificial insemination protocols in dairy cattle. J. Dairy Sci. 98:3826-3839. https://doi.org/10 $.3168 /$ jds.2014-9040.

NRC. 2001. Nutrient Requirements of Dairy Cattle. National Academy Press. Washington, DC.

Pereira, M. H., C. P. Sanches, T. G. Guida, A. D. Rodrigues, F. L. Aragon, M. B. Veras, P. T. Borges, M. C. Wiltbank, and J. L. Vasconcelos. 2013a. Timing of prostaglandin F2 $\alpha$ treatment in an estrogen-based protocol for timed artificial insemination or timed embryo transfer in lactating dairy cows. J. Dairy Sci. 96:28372846. https://doi.org/10.3168/jds.2012-5840.

Pereira, M. H., M. C. Wiltbank, L. F. Barbosa, W. M. Costa Jr., M. A. Carvalho, and J. L. Vasconcelos. 2015. Effect of adding a gonadotropin-releasing-hormone treatment at the beginning and a second prostaglandin F $2 \alpha$ treatment at the end of an estradiolbased protocol for timed artificial insemination in lactating dairy cows during cool or hot seasons of the year. J. Dairy Sci. 98:947959. https://doi.org/10.3168/jds.2014-8523.

Pereira, M. H., M. C. Wiltbank, and J. L. Vasconcelos. 2016. Expression of estrus improves fertility and decreases pregnancy losses in lactating dairy cows that receive artificial insemination or embryo transfer. J. Dairy Sci. 99:2237-2247. https://doi.org/10.3168/jds $.2015-9903$

Pereira, M. H. C., A. D. Rodrigues, R. J. de Carvalho, M. C. Wiltbank, and J. L. M. Vasconcelos. 2014. Increasing length of an estradiol and progesterone timed artificial insemination protocol decreases pregnancy losses in lactating dairy cows. J. Dairy Sci. 97:1454-1464. https://doi.org/10.3168/jds.2013-7287.

Pereira, M. H. C., A. D. P. Rodrigues, T. Martins, W. V. C. Oliveira, P. S. A. Silveira, M. C. Wiltbank, and J. L. M. Vasconcelos. 2013b. Timed artificial insemination programs during summer in lactating dairy cows: Comparison of the 5-d Cosynch protocol with an estrogen/progesterone-based protocol. J. Dairy Sci. 96:6904-6914. https://doi.org/10.3168/jds.2012-6260.

Pereira, M. H. C., C. P. Sanches Jr., T. G. Guida, M. C. Wiltbank, and J. L. M. Vasconcelos. 2017a. Comparison of fertility following use of one versus two intravaginal progesterone inserts in dairy cows without a CL during a synchronization protocol before timed AI or timed embryo transfer. Theriogenology 89:72-78. https://doi .org/10.1016/j.theriogenology.2016.10.006.

Pereira, M. H. C., M. C. Wiltbank, T. G. Guida, F. R. Lopes Jr., B. I. Cappellozza, and J. L. M. Vasconcelos. 2020. Evaluation of presynchronization and addition of GnRH at the beginning of an estra$\mathrm{diol} /$ progesterone protocol on circulating progesterone and fertility of lactating dairy cows. Theriogenology 147:124-134. https://doi .org/10.1016/j.theriogenology.2019.11.025.

Pereira, M. H. C., M. C. Wiltbank, T. G. Guida, F. R. Lopes Jr., and J. L. M. Vasconcelos. 2017b. Comparison of 2 protocols to increase circulating progesterone concentration before timed artificial insemination in lactating dairy cows with or without elevated body temperature. J. Dairy Sci. 100:8455-8470. https://doi.org/10 .3168/jds.2016-12145.

Peres, R. F., I. Claro Júnior, O. G. Sá Filho, G. P. Nogueira, and J. L. M. Vasconcelos. 2009. Strategies to improve fertility in Bos indicus postpubertal heifers and nonlactating cows submitted to fixedtime artificial insemination. Theriogenology 72:681-689. https:// doi.org/10.1016/j.theriogenology.2009.04.026.

Perry, G. A., M. F. Smith, M. C. Lucy, J. A. Green, T. E. Parks, M. D. MacNeil, A. J. Roberts, and T. W. Geary. 2005. Relationship between follicle size at insemination and pregnancy success. Proc. Natl. Acad. Sci. USA 102:5268-5273. https://doi.org/10.1073/ pnas.0501700102.

Peters, M. W., and J. R. Pursley. 2003. Timing of final GnRH of the Ovsynch protocol affects ovulatory follicle size, subsequent luteal function, and fertility in dairy cows. Theriogenology 60:1197-1204. https://doi.org/10.1016/S0093-691X(03)00120-1.

Pohler, K. G., M. Pereira, F. Lopes, J. Lawrence, D. Keisler, M. Smith, J. Vasconcelos, and J. Green. 2016. Circulating concentrations of bovine pregnancy-associated glycoproteins and late embryonic mortality in lactating dairy herds. J. Dairy Sci. 99:1584-1594. https://doi.org/10.3168/jds.2015-10192.
Ribeiro, E. S., A. P. Monteiro, F. S. Lima, H. Ayres, R. S. Bisinotto, M. Favoreto, L. F. Greco, R. S. Marsola, W. W. Thatcher, and J. E. Santos. 2012. Effects of presynchronization and length of proestrus on fertility of grazing dairy cows subjected to a 5-day timed artificial insemination protocol. J. Dairy Sci. 95:2513-2522. https: //doi.org/10.3168/jds.2011-4921.

Rispoli, L. A., R. R. Payton, C. Gondro, A. M. Saxton, K. A. Nagle, B. W. Jenkins, F. N. Schrick, and J. L. Edwards. 2013. Heat stress effects on the cumulus cells surrounding the bovine oocyte during maturation: altered matrix metallopeptidase 9 and progesterone production. Reproduction 146:193-207. https://doi.org/10.1530/ REP-12-0487.

Rivera, F. A., L. G. Mendonça, G. Lopes, J. E. Santos, R. Perez, M Amstalden, A. Correa-Calderón, and R. C. Chebel. 2011. Reduced progesterone concentration during growth of the first follicular wave affects embryo quality but has no effect on embryo survival post transfer in lactating dairy cows. Reproduction 141:333-342. https://doi.org/10.1530/REP-10-0375.

Roberts, C., G. Perry, M. Minten, A. Roberts, M. Macneil, and T. Geary. 2012. Effects of preovulatory estradiol concentration on embryo survival and pregnancy establishment in beef cows. Pages 98-102 in Proc. Western Section of Anim. Sci, Phoenix, AZ. American Society of Animal Science, Champaign, IL.

Ryan, D. P., J. F. Prichard, E. Kopel, and R. A. Godke. 1993. Comparing early embryo mortality in dairy cows during hot and cool seasons of the year. Theriogenology 39:719-737. https://doi.org/ 10.1016/0093-691X(93)90257-6.

Souza, A. H., H. Ayres, R. M. Ferreira, and W. C. Wiltbank. 2008. A new presynchronization system (Double-Ovsynch) increases fertility at first postpartum timed AI in lactating dairy cows. Theriogenology 70:208-215. https://doi.org/10.1016/j.theriogenology .2008.03.014.

Souza, A. H., A. Gümen, E. P. Silva, A. P. Cunha, J. N. Guenther, C. M. Peto, D. Z. Caraviello, and M. C. Wiltbank. 2007. Supplementation with estradiol-17beta before the last gonadotropin-releasing hormone injection of the Ovsynch protocol in lactating dairy cows. J. Dairy Sci. 90:4623-4634. https://doi.org/10.3168/jds.2007-0172.

Souza, A. H., S. Viechnieski, F. Lima, F. F. Silva, R. Araújo, G. A. Bó, M. C. Wiltbank, and P. S. Baruselli. 2009. Effects of equine chorionic gonadotropin and type of ovulatory stimulus in a timed-AI protocol on reproductive responses in dairy cows. Theriogenology 72:10-21. https://doi.org/10.1016/j.theriogenology.2008.12.025.

Torres-Júnior, J. R. S., M. F. A. Pires, W. F. Sá, A. M. Ferreira, J. H. M. Viana, L. S. A. Camargo, A. A. Ramos, I. M. Folhadella, J. Polisseni, C. de Freitas, C. A. A. Clemente, M. F. de Sá Filho, F. F. Paula-Lopes, and P. S. Baruselli. 2008. Effect of maternal heat-stress on follicular growth and oocyte competence in Bos indicus cattle. Theriogenology 69:155-166. https://doi.org/10.1016/ j.theriogenology.2007.06.023.

Townson, D. H., P. C. Tsang, W. R. Butler, M. Frajblat, L. C. Griel Jr., C. J. Johnson, R. A. Milvae, G. M. Niksic, and J. L. Pate 2002. Relationship of fertility to ovarian follicular waves before breeding in dairy cows. J. Anim. Sci. 80:1053-1058. https://doi .org/10.2527/2002.8041053x.

Vasconcelos, J. L., R. F. Cooke, D. T. Jardina, F. L. Aragon, M. B. Veras, S. Soriano, N. Sobreira, and A. B. Scarpa. 2011. Associations among milk production and rectal temperature on pregnancy maintenance in lactating recipient dairy cows. Anim. Reprod. Sci. 127:140-147. https://doi.org/10.1016/j.anireprosci.2011.07.012.

Vasconcelos, J. L., R. Sartori, H. N. Oliveira, J. G. Guenther, and M. C. Wiltbank. 2001. Reduction in size of the ovulatory follicle reduces subsequent luteal size and pregnancy rate. Theriogenology 56:307-314. https://doi.org/10.1016/S0093-691X(01)00565-9.

West, J. W. 2003. Effects of heat-stress on production in dairy cattle. J. Dairy Sci. 86:2131-2144. https://doi.org/10.3168/jds.S0022 -0302(03)73803-X.

Wildman, E. E., G. M. Jones, P. E. Wagner, R. L. Boman, H. F. Troutt Jr., and T. N. Lesch. 1982. A dairy cow body condition scoring system and its relationship to selected production characteristics. J. Dairy Sci. 65:495-501. https://doi.org/10.3168/jds .S0022-0302(82)82223-6. 
Wilson, S. J., C. J. Kirby, A. T. Koenigsfeld, D. H. Keisler, and M. C. Lucy. 1998. Effects of controlled heat stress on ovarian function of dairy cattle. 2. Heifers. J. Dairy Sci. 81:2132-2138. https://doi .org/10.3168/jds.S0022-0302(98)75789-3.

Wiltbank, M. C., R. Sartori, M. M. Herlihy, J. L. M. Vasconcelos, A. B. Nascimento, A. H. Souza, H. Ayres, A. P. Cunha, A. Keskin, J. N. Guenther, and A. Gumen. 2011a. Managing the dominant follicle in lactating dairy cows. Theriogenology 76:1568-1582. https:/ /doi.org/10.1016/j.theriogenology.2011.08.012.

Wiltbank, M. C., A. H. Souza, P. D. Carvalho, R. W. Bender, and A. B. Nascimento. 2011b. Improving fertility to timed artificial insemination by manipulation of circulating progesterone concentrations in lactating dairy cattle. Reprod. Fertil. Dev. 24:238-243. https://doi.org/10.1071/RD11913.

Wiltbank, M. C., A. H. Souza, P. D. Carvalho, A. P. Cunha, J. O. Giordano, P. M. Fricke, G. M. Baez, and M. G. Diskin. 2014. Physiological and practical effects of progesterone on reproduction in dairy cattle. Animal 8(Suppl. 1):70-81. https://doi.org/10 $.1017 /$ S1751731114000585.

Wolfenson, D., B. J. Lew, W. W. Thatcher, Y. Graber, and R. Meidan. 1997. Seasonal and acute heat stress effects on steroid production by dominant follicles in cows. Anim. Reprod. Sci. 47:9-19. https:/ /doi.org/10.1016/S0378-4320(96)01638-7.

Wolfenson, D., Z. Roth, and R. Meidan. 2000. Impaired reproduction in heat-stressed cattle: Basic and applied aspects. Anim. Reprod. Sci. 60-61:535-547. https://doi.org/10.1016/S0378-4320(00)00102 -0 .

Wolfenson, D., W. W. Thatcher, L. Badinga, J. D. Savio, R. Meidan, B. J. Lew, and R. Braw-tal., and A. and Berman. 1995. Effect of heat stress on follicular development during the estrous cycle in lactating dairy cattle. Biol. Reprod. 52:1106-1113. https://doi .org/10.1095/biolreprod52.5.1106.

Xu, Z., H. A. Garverick, G. W. Smith, M. F. Smith, S. A. Hamilton, and R. S. Youngquist. 1995. Expression of messenger ribonucleic acid encoding cytochrome P450 side-chain cleavage, cytochrome p450 17 alpha-hydroxylase, and cytochrome P450 aromatase in bovine follicles during the first follicular wave. Endocrinology 136:981-989. https://doi.org/10.1210/endo.136.3.7867608.

Younas, M., J. W. Fuquay, A. E. Smith, and A. B. Moore. 1993 Estrous and endocrine responses of lactating Holsteins to forced ventilation during summer. J. Dairy Sci. 76:430-436. https://doi .org/10.3168/jds.S0022-0302(93)77363-4. 